This document was prepared in conjunction with work accomplished under Contract No. DE-AC09-96SR18500 with the U.S. Department of Energy.

This work was prepared under an agreement with and funded by the U.S. Government. Neither the U. S. Government or its employees, nor any of its contractors, subcontractors or their employees, makes any express or implied: 1 . warranty or assumes any legal liability for the accuracy, completeness, or for the use or results of such use of any information, product, or process disclosed; or 2 . representation that such use or results of such use would not infringe privately owned rights; or 3 . endorsement or recommendation of any specifically identified commercial product, process, or service. Any views and opinions of authors expressed in this work do not necessarily state or reflect those of the United States Government, or its contractors, or subcontractors. 


\title{
The Use of Digital Radiography in the Evaluation of Radioactive Materials Packaging Performance Testing
}

\author{
Cecil G. May \\ Savannah River National Laboratory \\ Aiken, SC 29808
}

\begin{abstract}
New designs of radioactive material shipping packages are required to be evaluated in accordance with 10 CFR Part 71, Packaging and Transportation of Radioactive Material. This paper will discuss the use of digital radiography to evaluate the effects of the tests required by 10 CFR 71.71, Normal Conditions of Transport (NCT), and 10 CFR 71.73, Hypothetical Accident Conditions (HAC). One acceptable means of evaluating packaging performance is to subject packagings to the series of NCT and HAC tests. The evaluation includes a determination of the effect on the packaging by the conditions and tests. That determination has required that packagings be cut and sectioned to learn the actual effects on internal components.

Digital radiography permits the examination of internal packaging components without sectioning a package. This allows a single package to be subjected to a series of tests. After each test, the package is digitally radiographed and the effects of particular tests evaluated. Radiography reduces the number of packages required for testing and also reduces labor and materials required to section and evaluate numerous packages.

This paper will include a description of the digital radiography equipment used in the testing and evaluation of the 9977 and 9978 packages at SRNL. The equipment is capable of making a single radiograph of a full-sized package in one exposure. Radiographs will be compared to sectioned packages that show actual conditions compared to radiographic images.
\end{abstract}




\section{The Use of Digital Radiography in the Evaluation of Radioactive Materials Packaging Performance Testing}

\section{Introduction}

New designs of radioactive material shipping packages are required to meet the requirements 10 CFR Part 71, Packaging and Transportation of Radioactive Material. 10 CFR Part 71 establishes, in part, the testing that proposed packaging must undergo to be a certified packaging. Packaging must be tested under two conditions: 1) Normal Conditions of Transport (NCT) per 10 CFR 71.71; and, 2) Hypothetical Accident Conditions (HAC) per 10 CFR 71.73. Each package design must be evaluated to determine the effects that conditions and tests of NCT and HAC have on the design of the packaging.

The tests represent conditions typical of normal transportation and conditions that could be the result of an accident. The tests applicable to the packaging for this paper are:

Normal Conditions of Transport

Vibration

Water spray

Free drop (from $4 \mathrm{ft}$ )

Compression

Penetration
Hypothetical Accident Conditions

Free drop from $30 \mathrm{ft}(9 \mathrm{~m})$

Crush

Puncture

Thermal

The containment vessels of test packaging must survive the NCT and HAC tests and maintain containment of the radioactive material as specified in 10 CFR Part 71. In the case of the packaging described in this paper, the containment vessels maintained leaktightness during the series of tests. Leak-tight as described by ANSI 14.5 is less than $1 \times 10^{-7} \mathrm{ref} \cdot \mathrm{cm}^{3} / \mathrm{sec}$ of air leakage.

Tests are performed sequentially and packaging must be tested by the entire series of NCT and HAC tests to evaluate the cumulative effects of the tests. After each test the packages are evaluated for the effects of that test. In the past, test evaluations required packaging to be sectioned to evaluate the effects of a test on internal parts of the packaging. The Model 9977 packaging described in this paper was examined between tests with digital radiography. After testing was complete, packagings were cut apart and internal conditions compared to the indications shown on radiographs taken during the testing.

The Model 9977 packaging components are shown in Figure 1. Figure 2 illustrates the arrangement of the packaging components. 


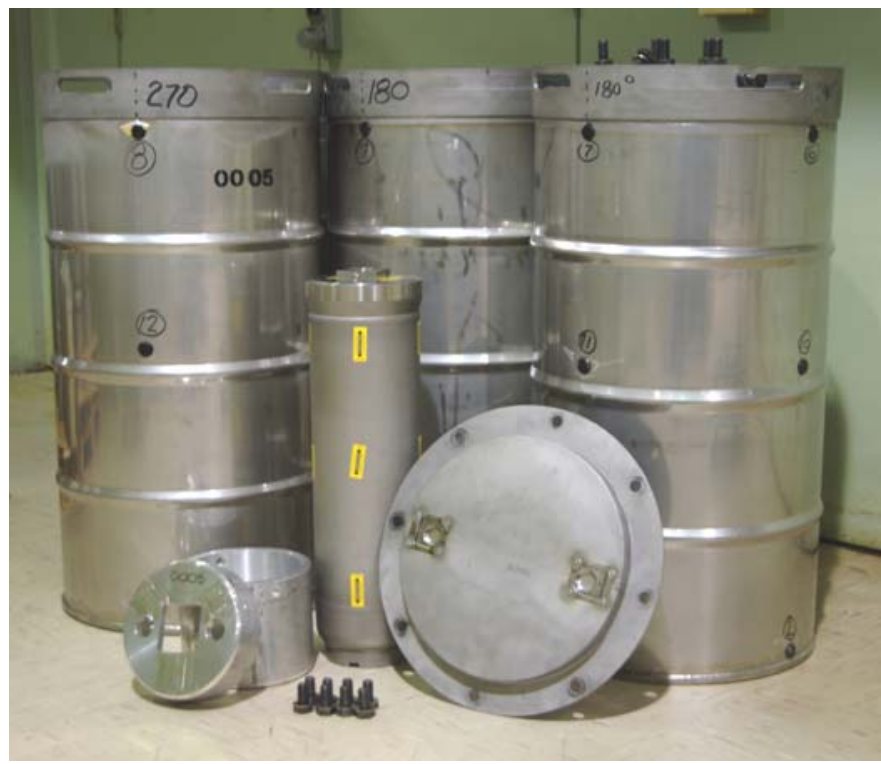

Figure 1. Model 9977 components

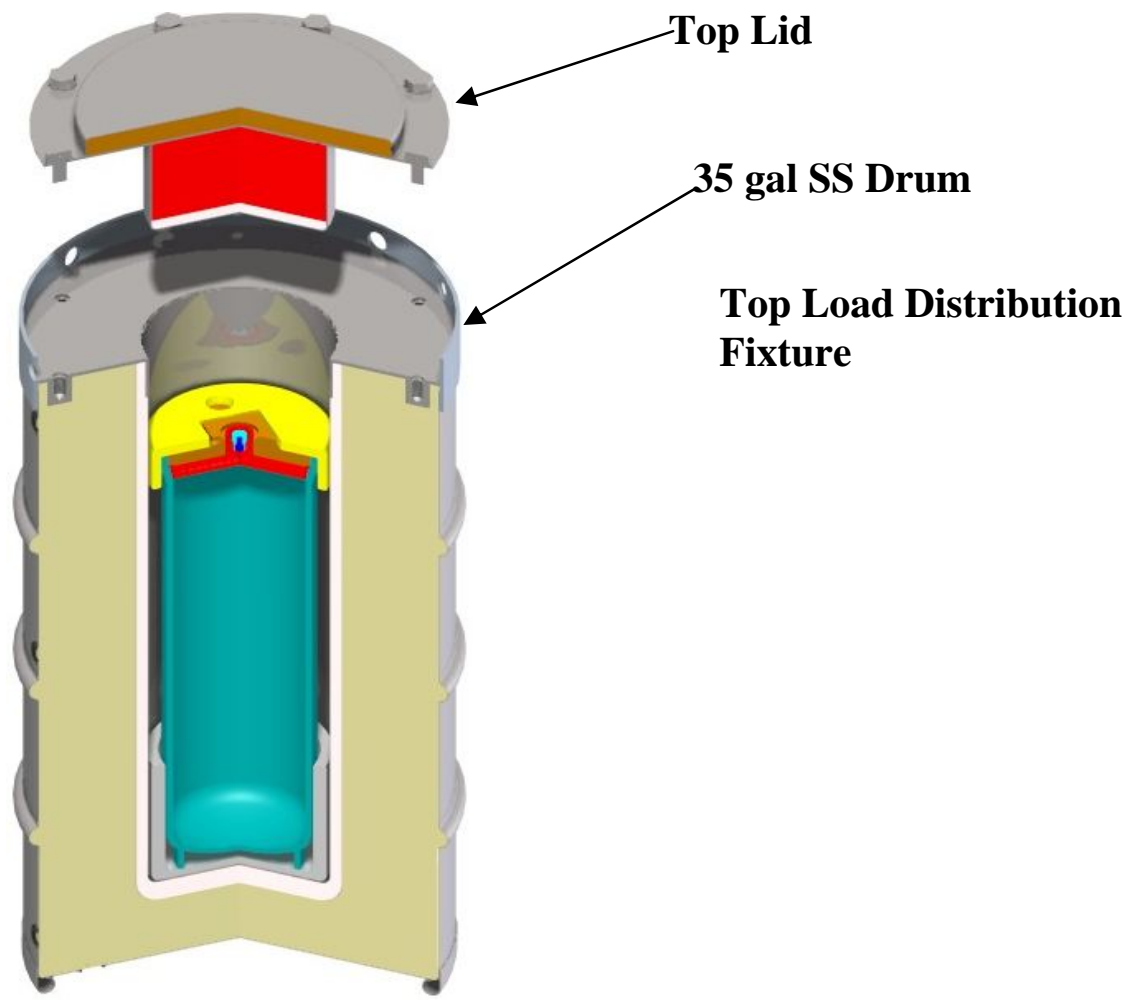

Figure 2. Arrangement of Model 9977 Components 


\section{Discussion}

\section{Digital Radiography Equipment}

The diagram in Figure 3 shows a typical lens-coupled, charge-coupled device (CCD) based, area detector, digital radiography imaging system configuration. The scintillator converts X-ray photons into light. The turning mirror allows the CCD camera to be placed outside of the highintensity X-ray beam. As the beam of Xrays pass through the test object, the scintillator's rare earth compound interacts with incoming $\mathrm{X}$-ray photons at the atomic level and a visible image appears on the scintillation panel. The image appearing on the scintillation panel is photographically

captured by the CCD camera and stored in the Figure 3. Typical DR Configuration computer.

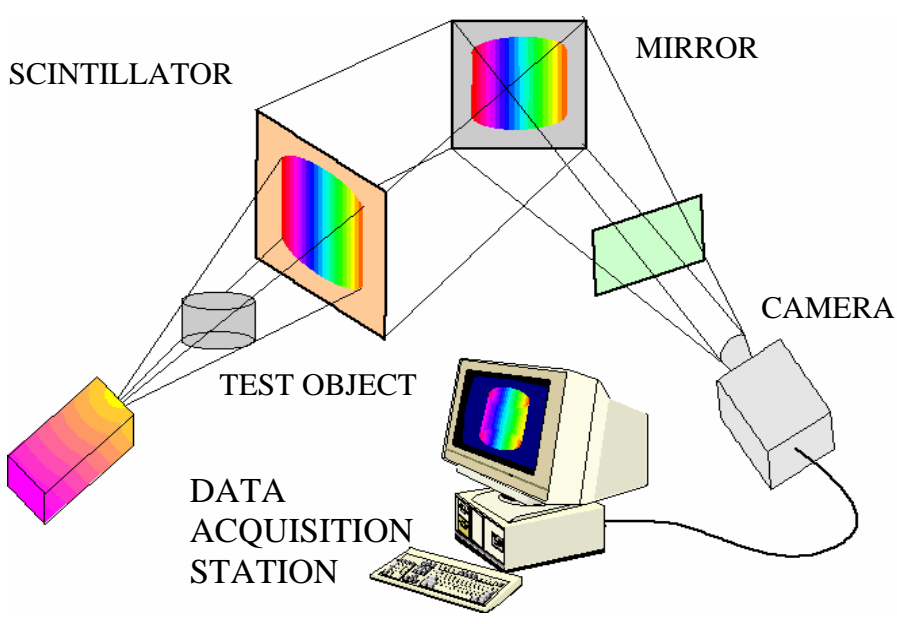

A digital camera with a scientific grade 1536 x 1024 pixel array, CCD chip was used to acquire all images. Lead shielding protected the camera and its electronics. A turning mirror was used to focus the CCD camera onto the scintillation panel and to keep the camera out of the direct X-ray beam. Optically transparent lead glass placed between the CCD camera and the turning mirror, minimized the effects of scattered X-ray photons impinging upon the camera; thus degrading the radiographic image.

The computer controlled acquisition station for the DR facility is located outside of the imaging enclosure. Each radiographic image is automatically stored in the computer for immediate analysis.

Shown in the photo in Figure 4 is a test drum positioned in front of the gadolinium oxisulfide (GOS) scintillation panel. The scintillation panel consists of multiple Optonix screens, tiled together. The platform on which the test drum sits has both vertical and rotational motions. The complete height and width of the package is captured in every view. Radiographic views of an entire drum were captured at rotational intervals of 30 degrees. Lead numbers around the circumference provide reference markers.

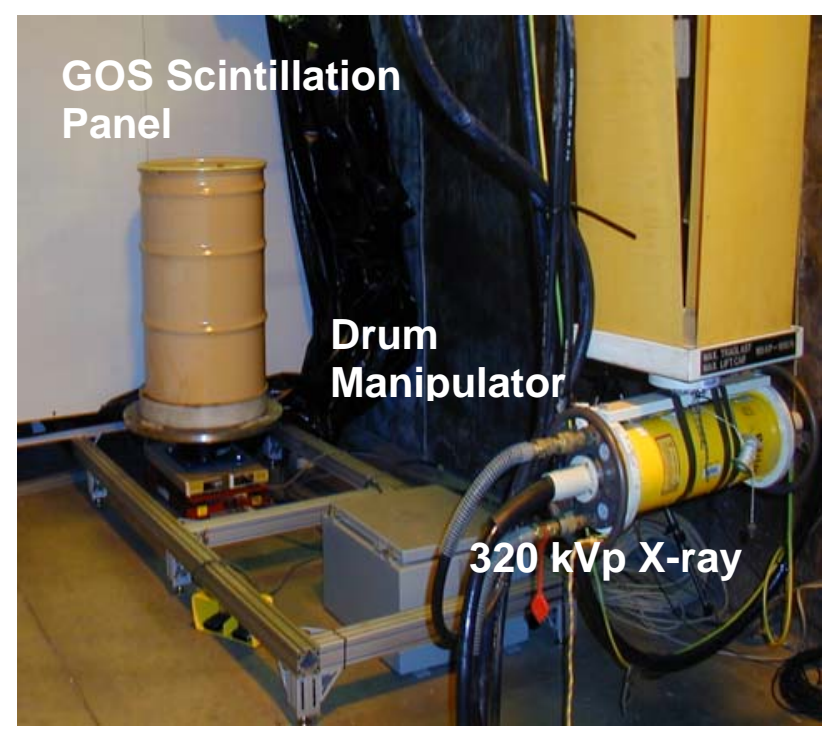

Figure 4. Digital Radiography Setup 
Figure 5 is a picture of the shielded camera, turning mirror, and leaded glass located behind the scintillation panel

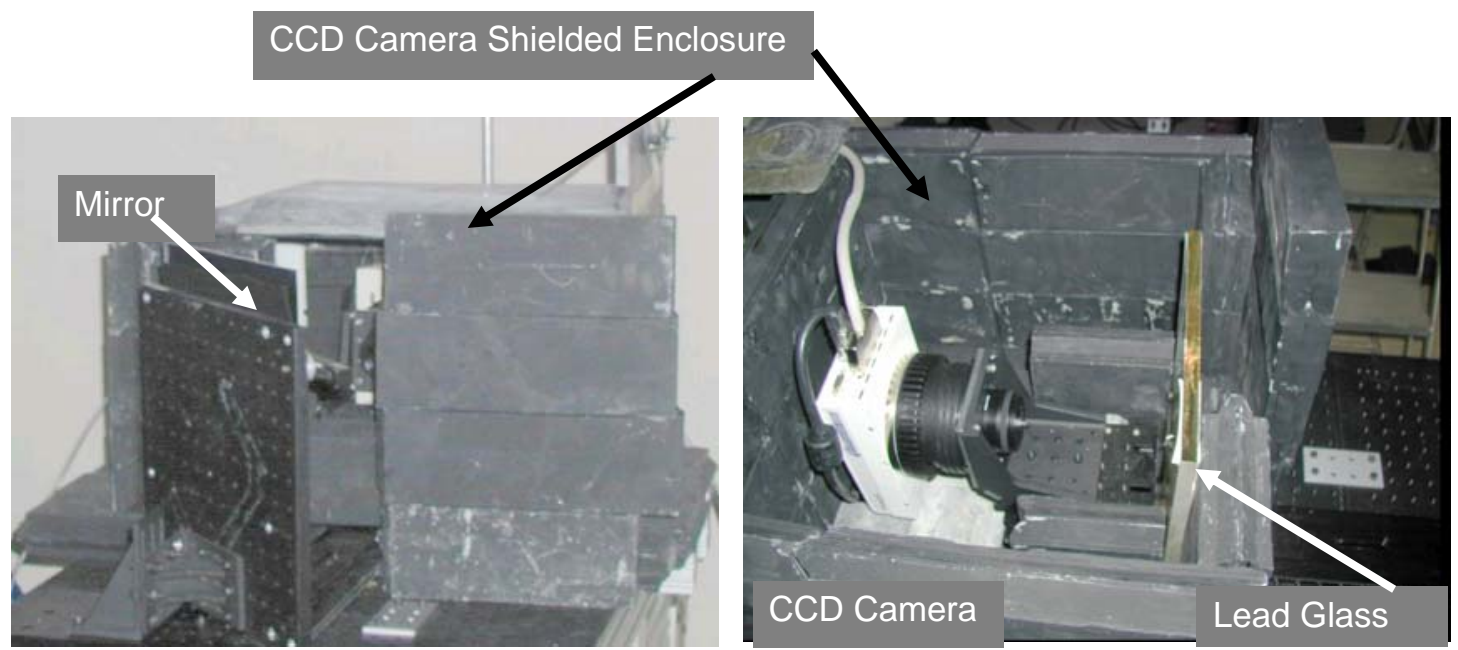

Figure 5. Camera shielding, turning mirror, and lead glass

\section{Baseline Radiographs}

Prior to the start of testing, radiographs were taken of the empty packages. These radiographs were used as a baseline for future radiographs. During the tests, a $100 \mathrm{lb}$ test weight was placed inside the containment vessel to simulate the maximum weight of the proposed contents. One prototype package was subjected to all the NCT and HAC tests in sequential order required by $10 \mathrm{CFR}$ Part 71 . Other packages were subjected only to the HAC tests. The radiographs after the NCT tests showed no detectable changes in the internal components of the package. Only radiographs taken during the HAC tests will be used as examples for this paper.

Figure 6 shows a typical baseline radiograph and the internal parts of the package. The baseline radiographs shows the internal condition of the packaging before testing begins. Two linear voids are present in the polyurethane foam that fills the internal cavity. The Fiberfrax ${ }^{\circledR}$ insulation blanket around the inner liner and at the bottom of the inner liner shows as a light line. At the bottom of the inner liner, the blanket appears to have separated from the liner. The top and bottom load distribution fixtures are located at the top and bottom of the containment vessel. The test weight is shown inside the CV. 


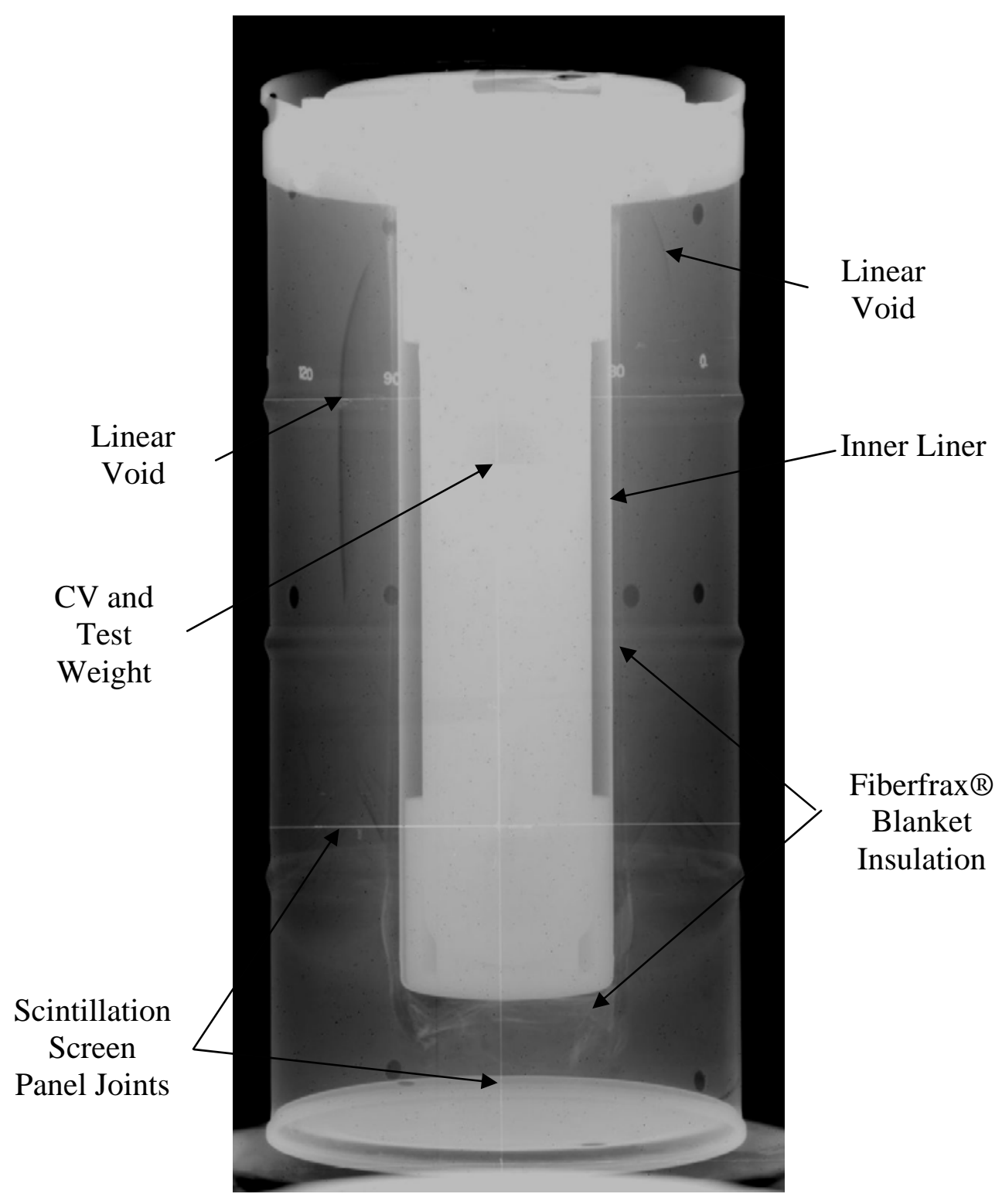

Figure 6. Typical baseline radiograph showing internal components and imperfections 
Packaging identified as SN-3 was subjected to HAC tests consisting of: 1) a 30-ft drop, 2) crush test, 3) puncture test, and, 4) a thermal test. The package was radiographed after the drop, crush, and thermal tests.

\section{$\underline{\text { 30-ft HAC Drop Test }}$}

In the 30-ft drop test, the package was dropped onto an unyielding steel plate set in concrete from a height of 30-ft. The package was dropped in the horizontal position and struck the plate horizontally at approximately the 330 degree area on the drum circumference. Figure 7 compares the baseline radiograph to radiographs taken after the

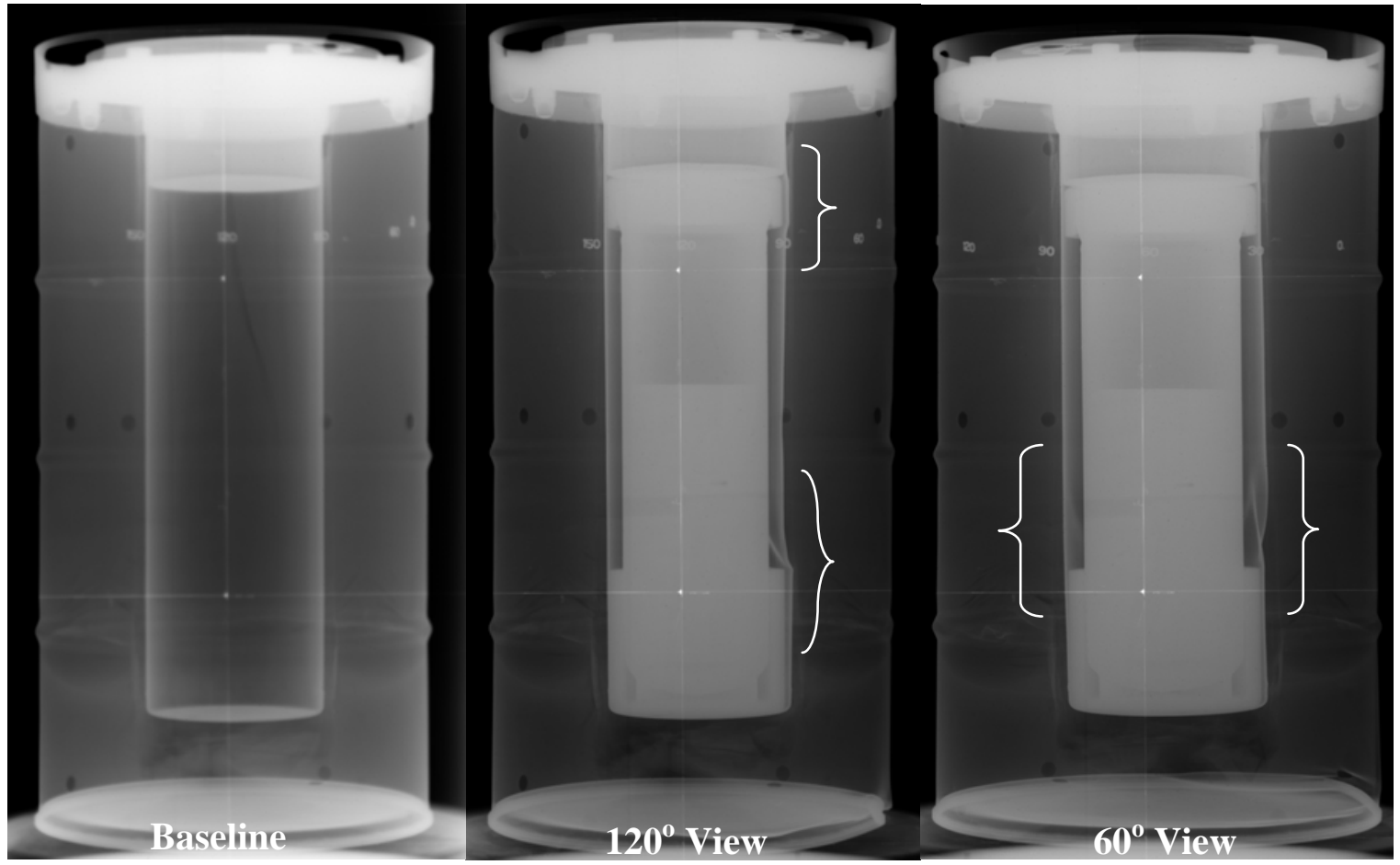

Figure 7. Comparison of baseline radiograph to $120^{\circ}$ and $60^{\circ}$ views after 30 -ft drop

drop. The areas at the bottom load distribution fixture of the inner liner show a buckling of the inner liner that holds the CV. The liner section at the top load distribution fixture is distorted from by the impact of the fixture against the liner during the drop. Based on a point of impact at approximately 330 degrees, the 120 degree view should show the most severe damage to the liner. Figure 8 gives a clearer view of the distortion of the inner liner at the top load distribution fixture. 


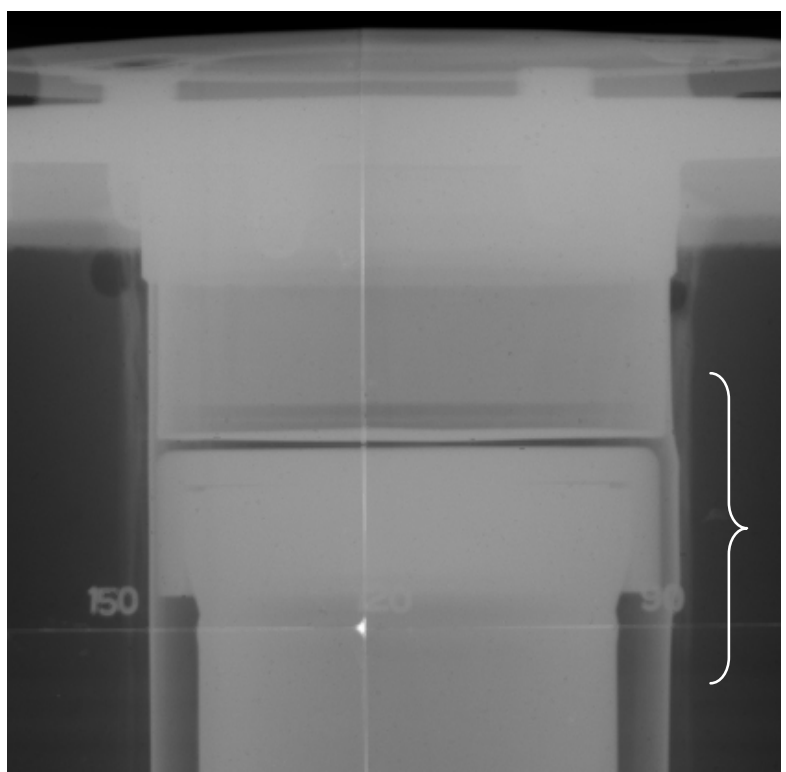

Figure 8. Distortion at top load

distribution fixture - post $-\mathbf{3 0}$-ft drop

\section{$\underline{\text { HAC Crush Test }}$}

The crush test consisted of dropping a 1100-lb, 2-in thick steel plate from 30-ft onto the

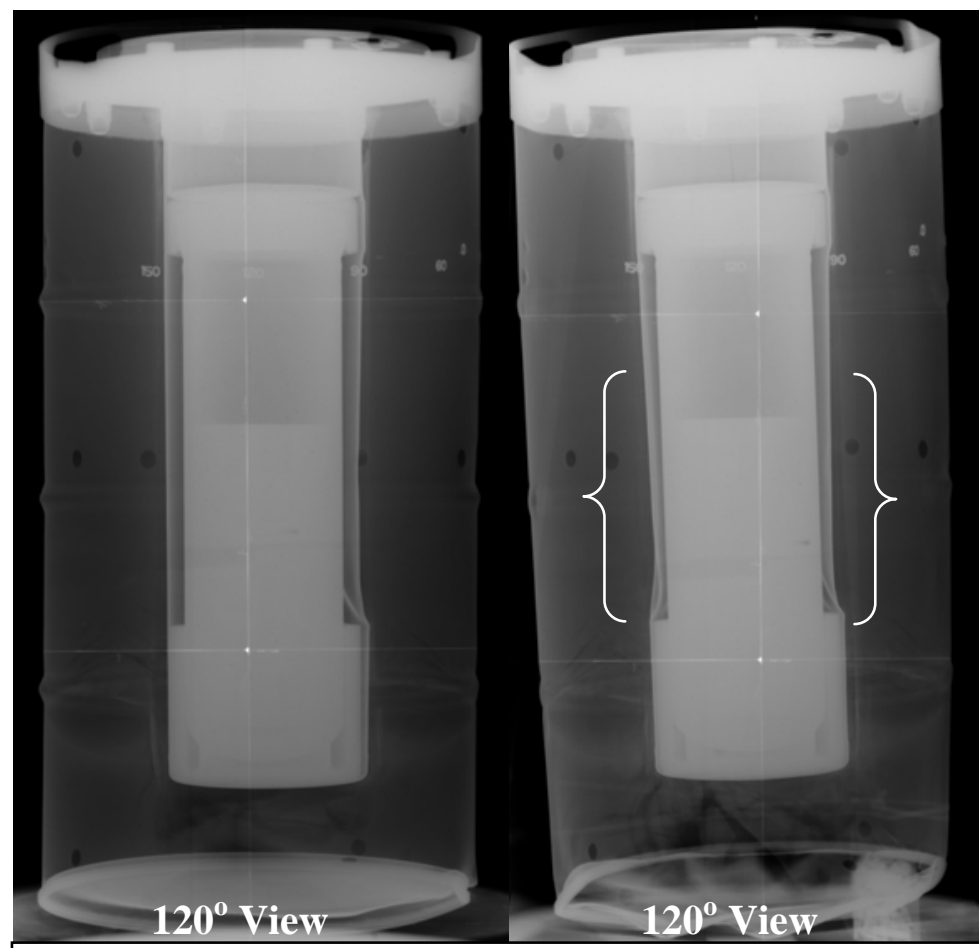

Figure 9. Left: Pre-crush radiograph $120^{\circ}$ view. Right: Post-crush $120^{\circ}$ view package. The package was oriented horizontally on a steel plate set in concrete to provide an unyielding surface. The steel plate struck the package at the same point of impact on the package (approximately 330 degrees) as in the drop test.

As seen in Figure 9, the inner liner is distorted even more by the crush test test. The indications under the bottom of the inner liner in pre-crush radiograph are much more pronounced after the crush test. This indicates damage to the polyurethane foam in this area. Damage to the bottom of the outer drum is obvious. 


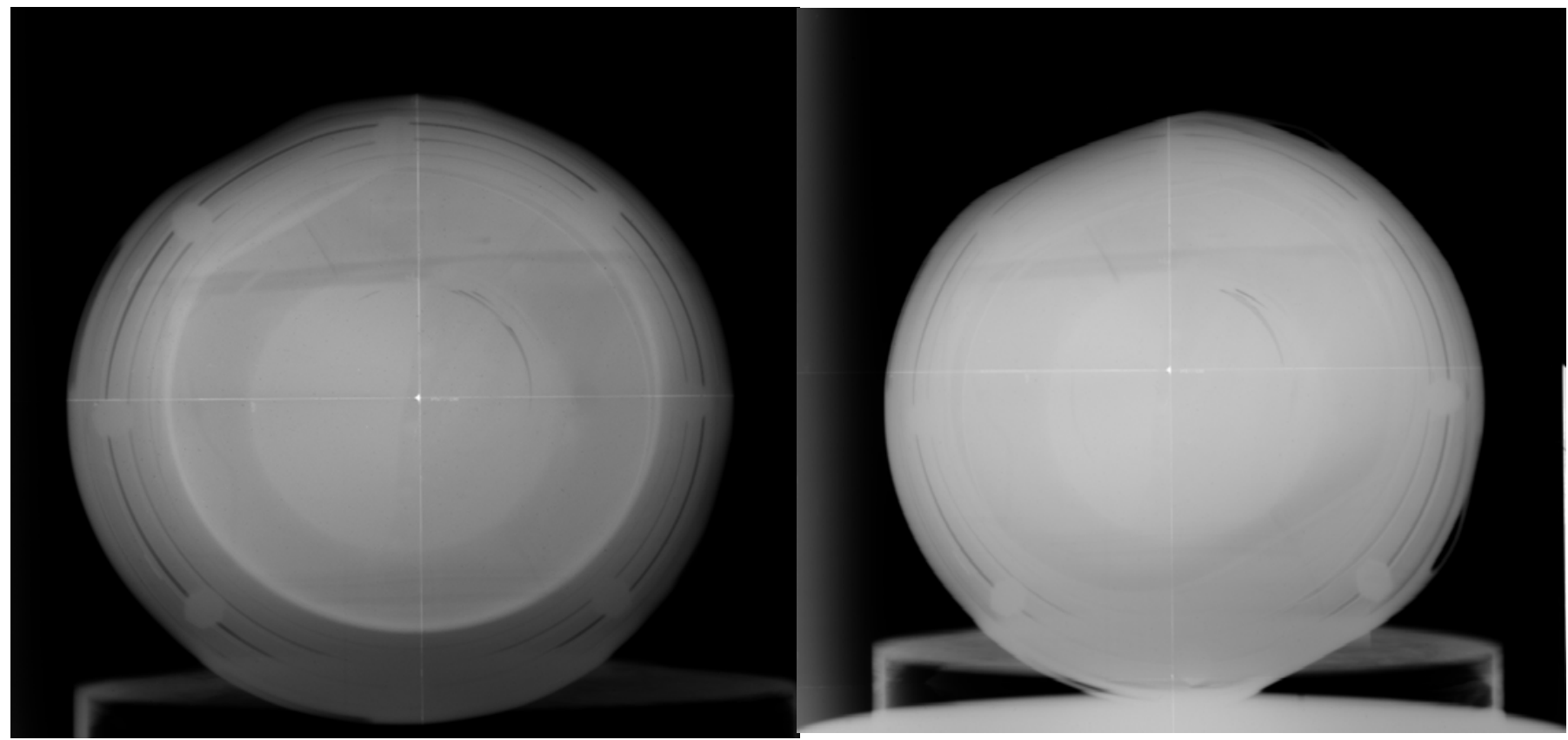

Figure 10. Left: End-to-end view after 30-ft drop. Right: End-to-end view after crush test. Both views indicate radial cracks in the foam.

\section{Thermal Test}

Following the puncture test, which requires dropping the package from a height of 40 -inches onto a 6-inch diameter steel pin, the package was exposed to an open flame at a

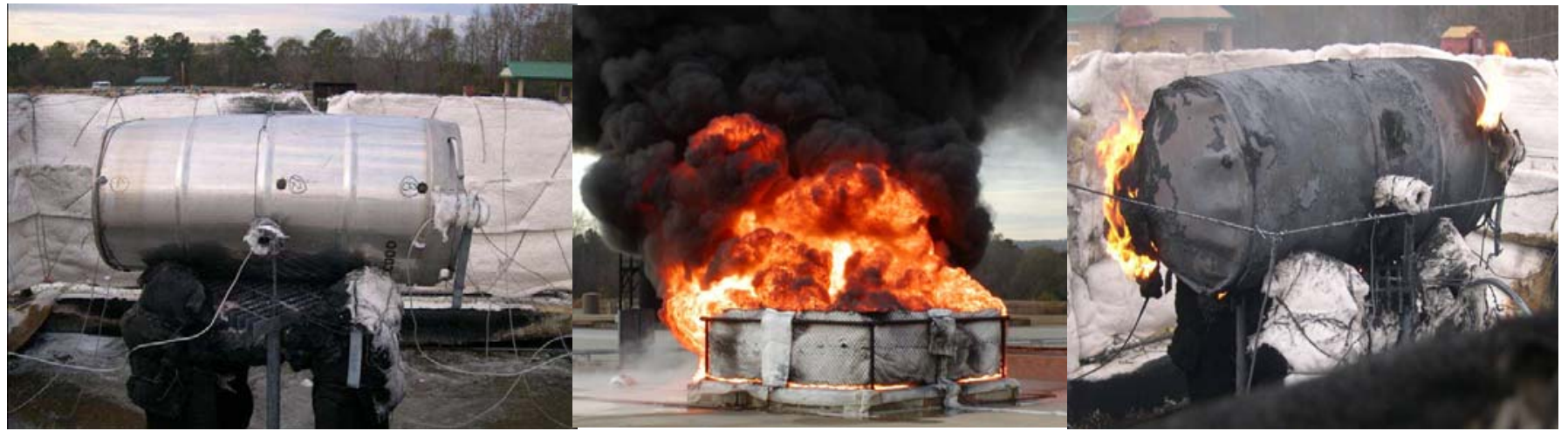

Figure 11. SN-3 before, during, and after the thermal test

temperature of $1475^{\circ} \mathrm{F}\left(800^{\circ}\right)$. The package was fully engulfed by the flame. Photos in Figure 11 show the package before, during the engulfing flame, and afterwards. The heat from the flames degraded the foam as can be seen in the radiographs in Figure 12. The radiographs indicate greatly deteriorated foam near the outer drum. In the end-to-end view, the foam is separated into two lobes. The areas where the foam is completely deteriorated to the Fiberfrax ${ }^{\circledR}$ insulation align with the radial cracks seen after the drop 
and crush tests (Figure 10). The two lobes still attached to the inner liner appear to be undamaged. The areas where the foam degraded vary in density indicating varying
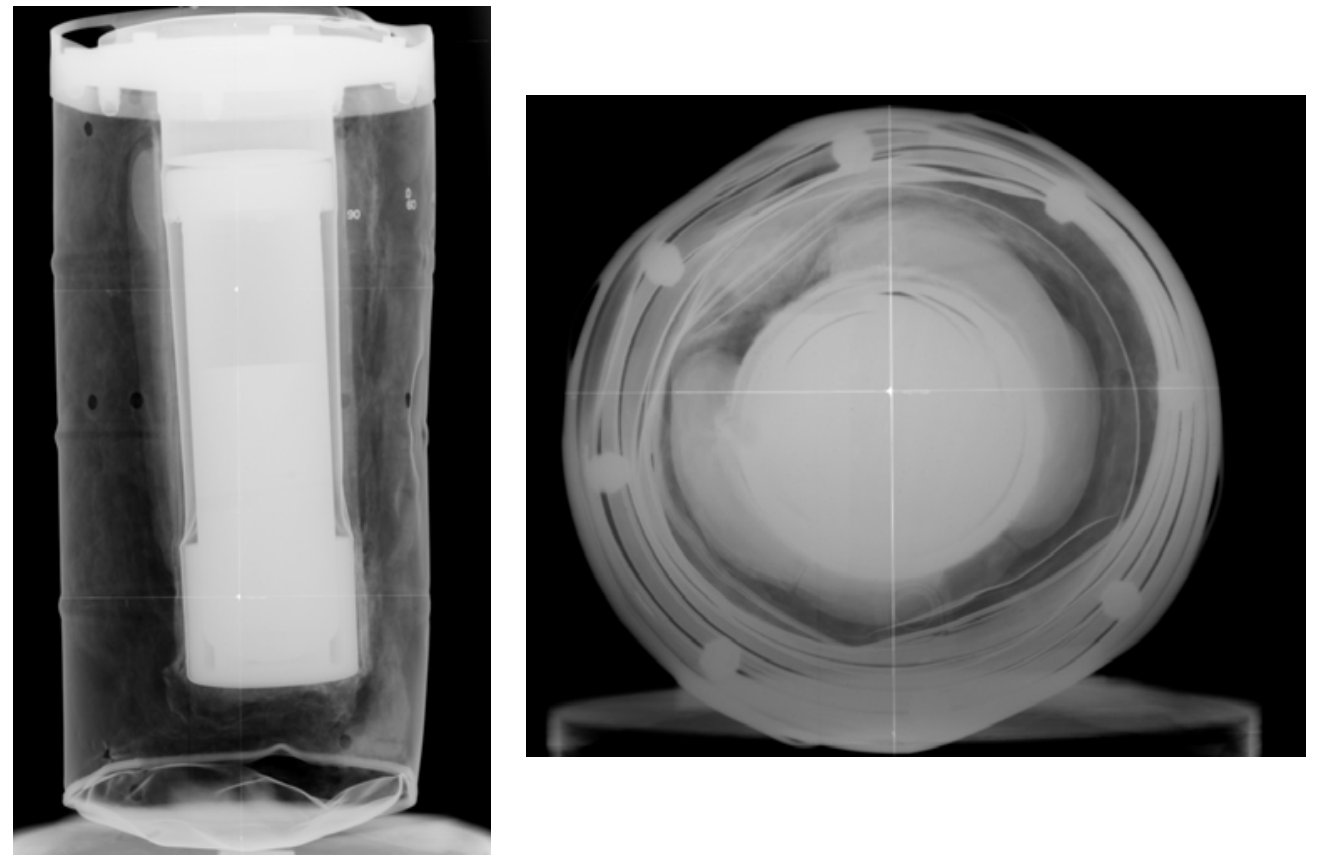

Figure 12. SN-3, Radiographs after thermal tests.

degrees of deterioration. The whole package radiograph shows an opening at the drum bottom that allowed the flames to come in direct contact with foam.

\section{Results}

Digital radiography images taken between each of the HAC tests show the effects each test had on the package. The radiographs were able to show the effect of each test and the cumulative effects of all the tests on the package design. At the end of the tests, each package was cut apart to remove the containment vessel for leak testing. In doing so, the interior of the packages were examined and the results substantiated indications seen in the radiographs. The thermal tests for all the packages degraded the foam to great extent. Some packages had a complete cocoon of undamaged foam around the inner liner. When the undamaged foam was sectioned, voids, both circumferential and radial, were found. These voids could be traced back to indications in the baseline and in-test radiographs. Examples of the voids and radiographic indications are shown in Figure 13. 

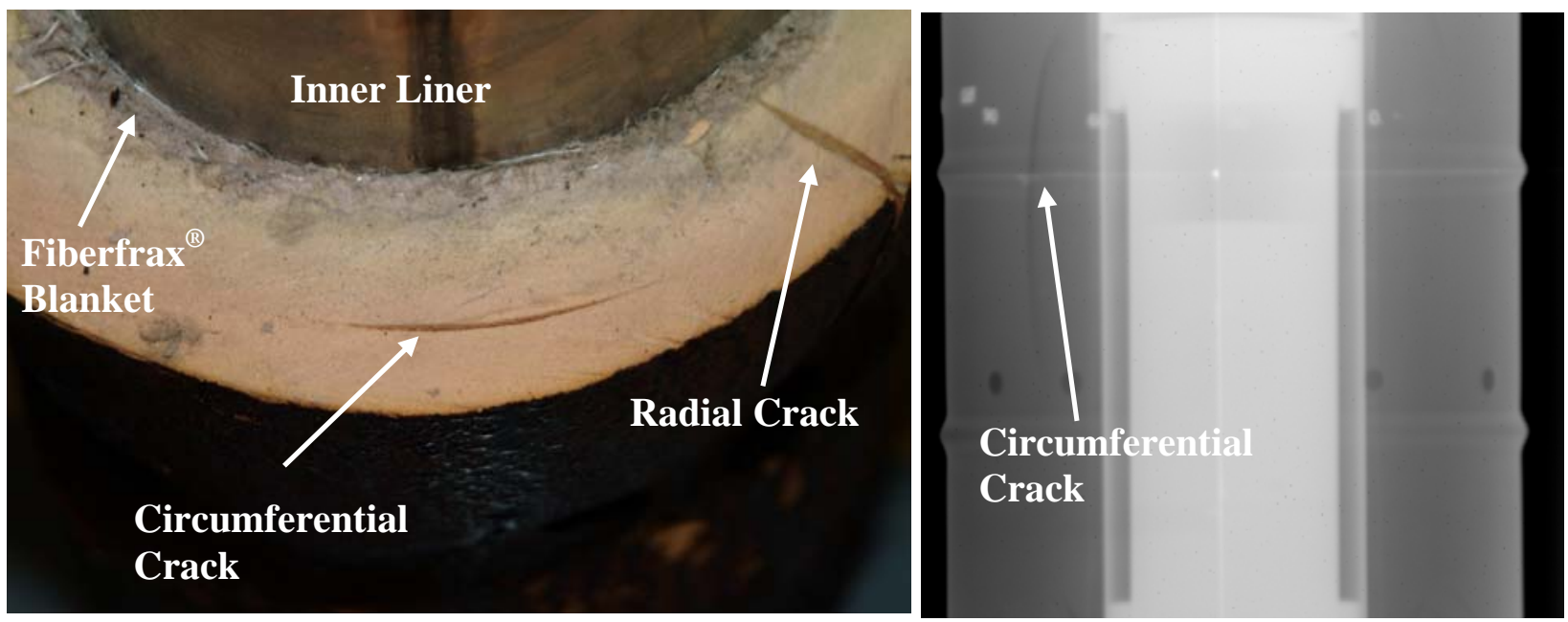

Figure 13. Comparison of actual cracks in the foam with radiographic indications

The sectioning of SN-3 showed thermal damage resulting from pre-existing voids during the thermal tests. Figures $14-16$ show the actual conditions compared to radiographic images.

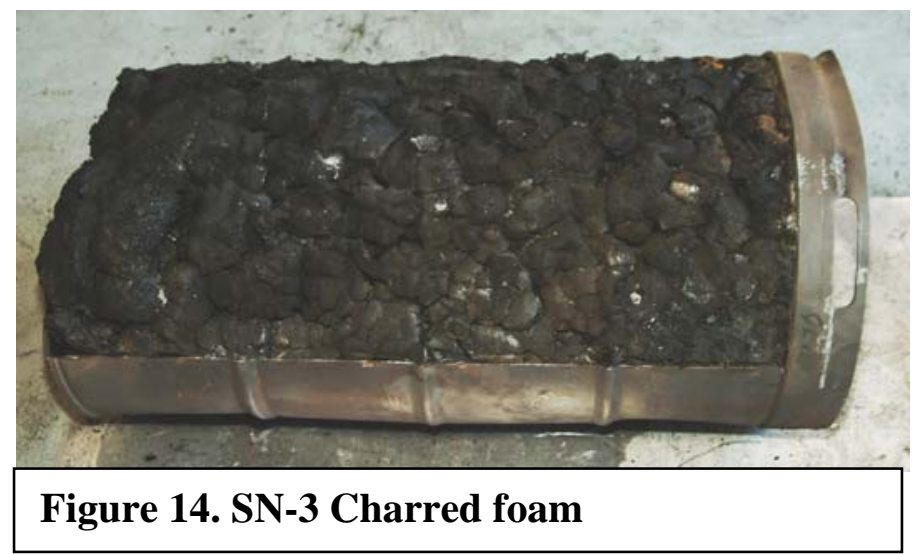

Figure 14 is a photograph of SN-3 after the outer drum shell was cut away. The foam is a nodular shaped with varying degrees of charring. The nodular shape and varying densities resulted in the different densities in the radiographs.

Figure 15 is an example of the heat and flames of the thermal test attacking a defect in the foam that resulted localized charring of the foam. The areas where the foam is charred to the Fiberfrax ${ }^{\circledR}$ insulation were where defects in the foam existed. The radiographs in Figure 10 have indications of radial cracks at the $150^{\circ}$ and $330^{\circ}$ locations. 


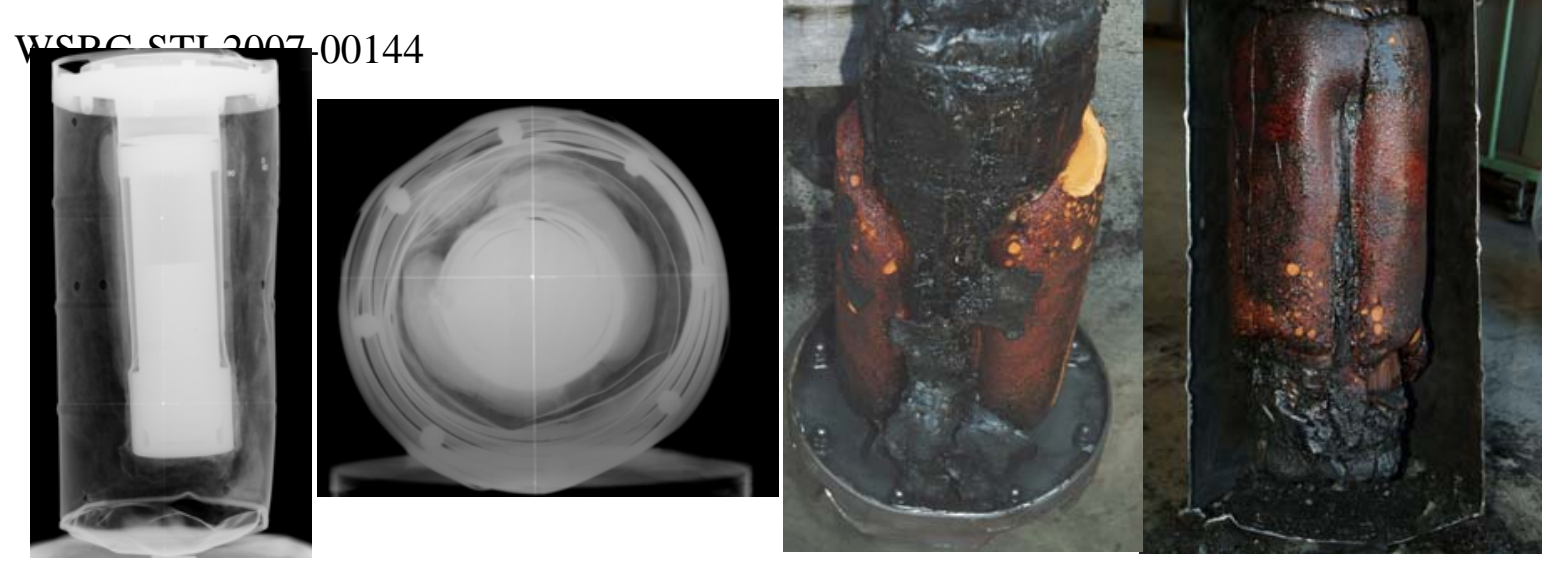

Figure 15. SN-3. Photographs showing deteriorated foam at the 150 degree and 330 degree locations. Same locations that radial cracks were indicated after the drop and crush tests.

Figure 16 compares the deformation in the inner liner with the radiographs taken after the drop and crush tests. The outlines of both bottom and top load distribution fixtures are seen in the photographs. Both, including the buckled area, are seen in the radiographs. 


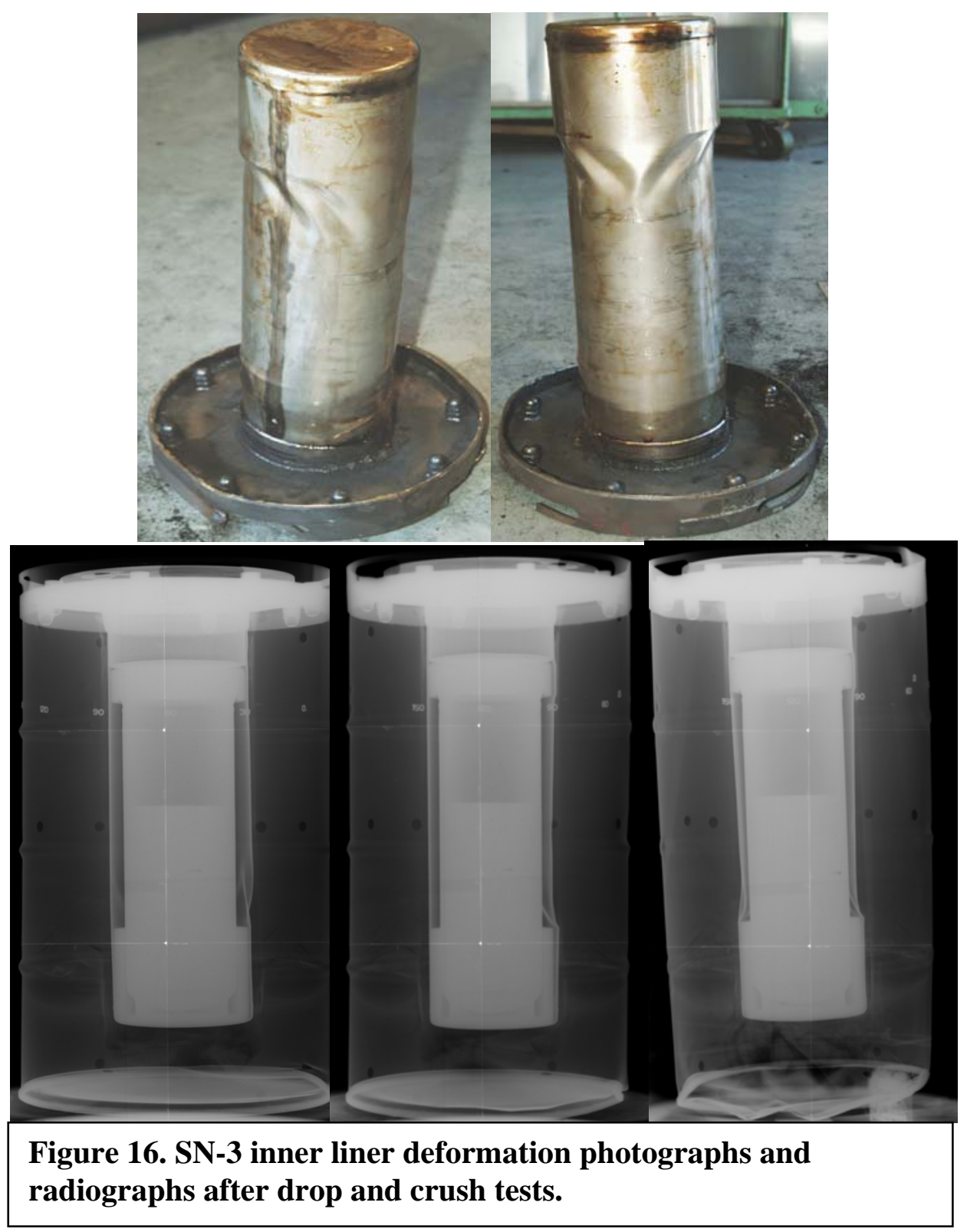

